\title{
Preface to Special Issue on Stress
}

\author{
David I. Mostofsky
}

Published online: 21 December 2010

(C) Springer Science+Business Media, LLC 2010

As we entered the twenty-first century, two long-standing concepts that fascinated researchers and theoreticians appear to be enjoying center stage in current publications and lecture forums, viz stress and happiness. Of particular interest is that both impact consequent effects and outcomes and modify, modulate, and mediate behaviors that often evolve from strikingly disparate theoretical orientations. Stress has a long history but gained special prominence with the pioneering work of Walter Cannon and Hans Selye with subsequent modifications by Erickson, McEwen, Sapolsky, and others. At one level, stress energizes us to "fight" or "flight", to complete our assignments, and to take note of our body distress. Short of extreme frontal lobe damage, we never truly wish ourselves to be totally free of stress. It fuels much of our daily activities; it is omnipresent. As a construct in the social sciences, stress has played a pivotal role in the evolution of psychosomatic theory, in understanding interpersonal and social psychological phenomena, and in contributing to the clinical management of many non-mental health disorders. It has also been addressed by the most serious neuroscientists and in turn has enriched the world of physiological theory and experimentation. Recent advances in physiology and neuroscience have exploded the volume of reexaminations and discussions of the neurobiological aspects of stress. The list of journal articles, monographs and reviews, and book publications is staggering.

Happiness, for its part, has realized a re-birth after decades of study and philosophical examination. In the context of psychology, it has focused on the dysfunctional,

D. I. Mostofsky ( $\square)$

Boston University, 64 Cummington Street, Boston, MA 02215, USA

e-mail: david.mostofsky@gmail.com abnormal, and genetically unkind outcomes and only recently has challenged us to reflect more intensely on good quality-of-life issues. It has only recently emerged from years of being relegated as a weak and unscientific term having only some romantic link to philosophical discourses and has taken its place alongside sophisticated and more rigorous concerns of contemporary psychology, sociology, economics, and the socio-biological sciences in general.

Both stress and happiness can exist concurrently within the same person, society, or age group but such comparisons risk becoming odious and leaving the reader more confused and less informed than ever. To be sure, both stress and happiness have found strong supporters and distracters in the biological worlds of neuroscience and biological markers. Because development and adult functioning is the mandate of this Journal, it seemed appropriate to bring to the attention of the Journal's readership several selected original, diverse, and relatively brief writings that mirror some of the training, theoretical perspectives, and interests that exist in the academic, clinical, and professional arenas at large. The selections were designed to represent issues that are not reflexively identified with the study of stress and to discuss conceptual and experimental models from segments of our discipline that are separated from the basic neuroscience contexts. We invite the reader to appreciate each presentation from its own perspective and orientation and to discover the contribution it can make to its neighboring construct of "happiness" in ways that previously might not have been apparent. 